\title{
Cecum Neoplasm
}

National Cancer Institute

\section{Source}

National Cancer Institute. Cecum Neoplasm. NCI Thesaurus. Code C4433.

A benign or malignant neoplasm that affects the cecum. Representative examples of benign neoplasms include lipoma and leiomyoma. Representative examples of malignant neoplasms include carcinoma, lymphoma, and sarcoma. Cecal adenomas always exhibit epithelial dysplasia and are considered premalignant neoplasms. 